\title{
- Integration of phasing on multi-objective optimization of building stock energy retrofit
}

3

4

5

6

7

\section{\& Abstract}

9 This article presents the integration of phasing (ie. temporal distribution of retrofit actions over time) into

June 4, 2021 


\section{${ }_{23}$ Highlights}

- Optimal retrofit plans for building stocks are generated using genetic algorithm

- The phasing of retrofit actions is integrated in the optimisation search space

- Results show that proposed optimal strategies are different when phasing is integrated

\section{Keywords}

Multi-objective optimization; building stocks; retrofit; phasing; planning

\section{Introduction}

According to the International Energy Agency [1], buildings are responsible for $30 \%$ of the worldwide primary energy use. The energy efficiency of buildings is a key to meet the ambitious target of $1.5^{\circ} \mathrm{C}$ of climate change. The Intergovernmental Panel on Climate Change suggests a decrease of building energy demand of 8 to $14 \%$ by $2030[2]$ in order to meet with proposed scenarios.

In addition, the building stock is renewed in France at a 1\% yearly rate [3] and existing buildings are often considered architectural heritage [4]: the highest potential for energy savings therefore lies in retrofitting the existing building stock. Generally, property managers base their retrofitting decisions on expert knowledge, then attempt to balance and optimize these decisions with constraints such as the global cost, including public financial assistance, energy efficiency, or comfort of the tenants. Although the solutions proposed by experts are generally suitable, they are not necessarily the most efficient.

A step further could be to automatize the balancing of the constraints with simple methods like weighted sum or weighted product. The proposed solution would then be part of the optimal solutions, but would be unique [5]. This limits the power of the decision maker: such methods could thus suffer of a low acceptability because of the lack of control on the process [6]. The weighted sum method suffers from another drawback, which is the difficulty to rank objectives among themselves. This difficulty has also been showed in different approaches at building stock level using multi-criteria decision aid methods like REDIS [7]. Consequently, multi-objective optimization (MOO) is a promising approach to efficiently propose a set of optimal solutions so the experts may focus on selecting one solution among several optimal candidates. Among MOO methods, 
genetic algorithms has been extensively used to optimize building retrofit, as stated in the review of CostaCarrapiço [8].

Multi-objective optimization has also been used to set up energy policies at larger scales. Tools have been developed to allow the evaluation of energy efficiency measures at city scale such as Stockholm [9]: buildings are first broken down into clusters and three energy conservation measures are evaluated regarding $\mathrm{CO}_{2}$ emission, heat demand and economic criteria. A similar approach has been carried out at the region level in Italy [10] and assesses energy efficiency measures based on a cost-benefit approach on environmental and economic criteria. Such methods help decision makers generate efficient energy policies but do not enable planning if and when the measures will be implemented.

In order to be useful to decision makers, MOO should be as close as possible to the real-life construction management workflow. A key point of any building stock management is the phasing plan of the construction work. The phasing of a construction work is how each action is broken down and arranged on a timeline with respect to construction constraints, site requirements, or time constraints. This timeline can last from less than a month on simple construction sites to a few years when dealing with a whole neighbourhood or a building stock managed by the same owner.

Phasing has been extensively studied in civil engineering at the construction site level [11] in order to optimize the scheduling of the construction. The prioritization of retrofit between multiple buildings has been studied by [12] with the seismic risk as an objective function. This objective function is calculated with subjective weights given to each variable of the problem (economy, safety, regulations) in order to come up with a mono-objective optimization problem. This is an efficient method if the decision maker is able to affect a weight to each objective, but it can only be applied if all objectives may be ranked. Another way to deal with the phasing plan of construction is the use of a risk-based approach to carry out decisions about the retrofit. Taillandier [13] qualitatively evaluates whether an action should be undertaken or not and aims to rank actions. However, each action must be proposed by an expert: the method loses efficiency as the size of the building stock increases. Moreover, the choice of action is subjective as the expert is influenced by his experience. Finally, Rivallain [14] proposed a method to sequence each retrofit action for optimization. This method was applied to two small fictional buildings and was limited to one retrofit action per year.

The purpose of this paper is to propose a formulation of temporal arrangement of retrofit strategies in the multi-objective optimization of a building stock, and then observe whether including this temporal dimension has any impact on the strategies proposed by optimization. This approach aims to get closer to the real world practice and to enable the planning of efficient retrofit projects for building stocks thanks to 
multi-objective optimization. In our terminology, the term of "stock" refers to a set of buildings managed by a unique property owner, with shared portfolio for refurbishment funds (e.g. social housing). The paper first describes the general framework for the optimization, then details the specifics of the implementation of temporal phasing in the optimization. Finally, outputs of the optimization are compared in order to put forward the effect of the integration of temporal distribution of construction on optimal retrofit strategies.

\section{Optimization methodology}

In order to allow optimizing different and often contradictory objectives, we use multi-objective optimization.

The formulation of the problem plays a significant role in the success of the process and in the interpretability of the results. Thus the problem should be carefully formulated with regards to which parameters to optimize, the decision space including the possible values of parameters, and the objective functions of the model.

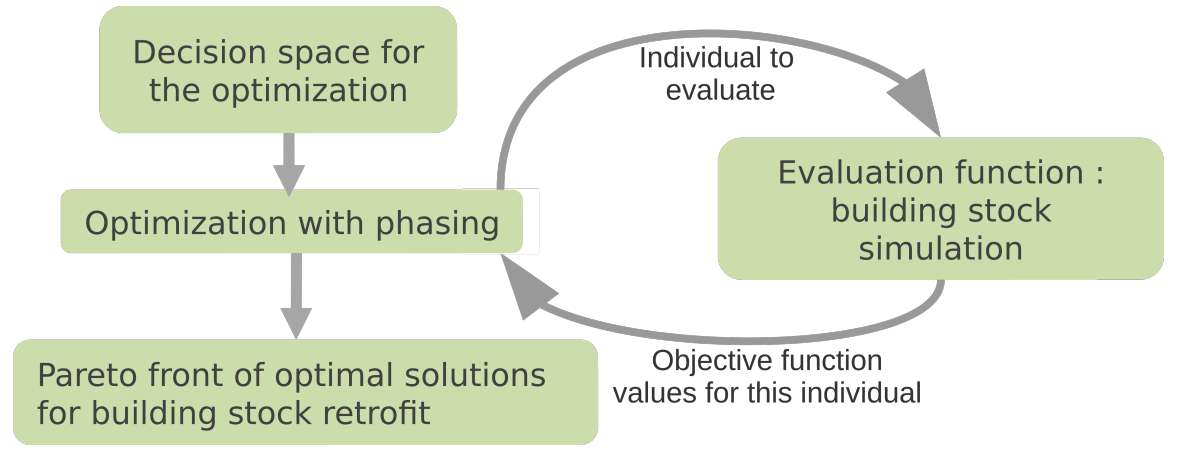

Figure 1: General optimization workflow

Figure 1 illustrates the global optimization process: in our case the aim is to generate optimal retrofit strategies for a building stock, which will form a set of candidates for decision (Pareto front). The global optimization process can be broken down into 3 main parts:

- the optimization algorithm which should consistently find optimal solutions;

- the decision space which is an input of the optimization algorithm;

- the objective functions in which the building stock performance are evaluated.

The objective function receives an individual to evaluate, which details the retrofit strategies components. This is part of the optimization algorithm which is chosen in section 2.3.

Each of these components is detailed hereafter. 


\subsection{Objective functions}

Building managers are optimizing retrofit plans on various objectives covering energy, environment, comfort of the tenants, costs... As a starting point, we choose to optimize retrofit strategies based on 3 objective functions selected in different fields based on the importance of the criteria for building managers in social housing. Thus the following objective functions are selected:

- Heating demand : weighted average of the heating needs in $\mathrm{kWh} / \mathrm{m}^{2}$ of all of the buildings for all of the years of the retrofit plan

- Overheating : sum of the ${ }^{\circ} \mathrm{C}$.hours above the $90 \%$ operative temperature comfort zone [15] over all years of the retrofit plan

- Cost : sum of the costs (in $€$ ) of all retrofit actions (global construction budget)

Concerning the overheating objective, it should be noted that in France, air conditioning is generally not provided in residential buildings. Summer comfort is an increasing concern as heatwaves occurrences become more frequent.

The definition of the time span is important, as it may impact the choice of retrofit actions. Here the time span of 20 years has been chosen, matching the average lifetime of retrofit actions. Indeed, datasheets for insulation materials show a lifetime of 15-25 years when properly implemented. Windows' lifetime lies between 20 and 25 years according to manufacturers.

\subsection{Decision space}

The decision space is composed of the possibles values for all parameters to be varied through the optimization process. In our case, the decision space was designed using the expert knowledge of engineering offices that completed multiple energy retrofits as project manager and as on-site management.

Each of the retrofitting actions is broken down into elementary tasks that deal with one component of one building (e.g. Change insulation: 12cm of rockwool on ceiling of building 1).

An example of decision space is available in the section 3. 


\subsection{Optimization algorithm}

The characteristics of our problem guide the choice of the optimization algorithm:

- The decision space is discrete. For instance, insulation materials are available in a limited number of thicknesses, and thus of R-values.

- It is preferable to keep multiple separate objectives, rather than a single weighted sum of indicators for the decision makers to be able to apply preferences later on.

Thus, genetic programming is a suitable approach to deal with this problem. As shown by Evins [16], other optimization methods do not meet our needs on either of the two points listed above while limiting the number of evaluations needed. Within genetic programming, the NSGA2 ([17]) algorithm has been widely used and its robustness has been validated by multiple studies in building physics $[16,18]$. Finally, it is applicable to large decision spaces, such as large combinatorial problems that can occur when dealing with building stocks.

Genetic algorithms mimic evolution by reproducing a population of individuals, and adapting them to their environment. In the end of the evolutionary process, only optimal individuals to their environment remain : they were optimized according their objective of survival in this environment. An individual features its chromosome, which is a representation of the set of parameters, and its fitness, which is the performance of the individual on each objective function. In each chromosome, one gene represents one parameter of the model to optimize. In order to explore the decision space of possible values for the parameters, chromosomes may vary through mutation or crossover.

We chose to use an efficient implementation of NSGA2 available in the DEAP Python library [19]. This implementation stands out with its improvement of the calculation of the crowding distance, as detailed in Fortin and Parizeau [20].

\subsection{Integration of temporality in optimization}

The main goal of our work is to integrate temporality in the multi-objective optimization algorithm with different levels of complexity while being able to compare the outputs of the optimization. We chose to implement 2 types of temporality in the optimization: sequencing and phasing. They will be compared with a base scenario, excluding temporality issues. 


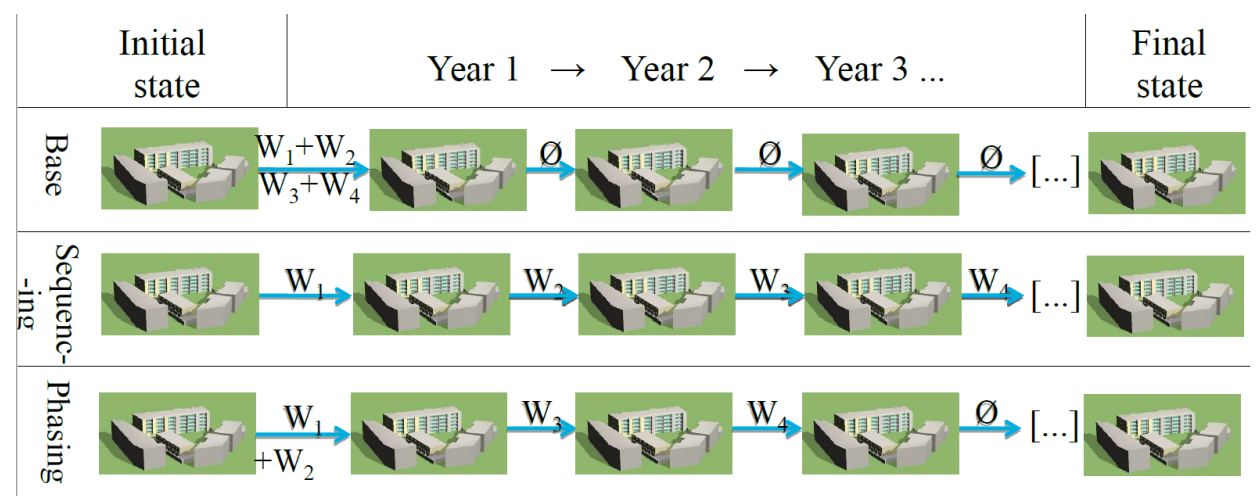

$\mathbf{W}_{\mathbf{i}}$ : elementary retrofit action on one part of one building (e.g. changing windows of building $i$ )

$\varnothing$ : no action carried out this year

Figure 2: Workflow for base and sequenced optimization

In the base scenario, all operations are carried at the beginning of the first year. This is the reference scenario, which will be used to compare the outcome of the other scenario. No constraints were imposed on the budget either on base or sequenced optimization.

\subsubsection{Implementations of sequencing}

Sequencing is the first step in adding temporality in the retrofitting actions. In this approach, presented in Figure 2, one retrofit action is carried out every year on one building (e.g On year 2, insulation is replaced with 10cm of rockwool on Ceiling of building 2).

The implementation of sequencing into the optimization algorithm is proposed by adding an extra chromosome that describes the temporality of actions. Consequently, each individual has now two chromosomes, as shown in Figure 3.

As previously stated, only one retrofit action is carried out at each stage (here, each stage equals one year). Consequently, in the case of sequencing, the chromosome that describes the temporality, visible on Figure 3, cannot include duplicate values, which means that specific mutation and crossover operators should be used. [21] proposed a crossover operator that respects the discrepancy and does not slow down nor reduces diversity [22]. 
Type of Ext. Walls of building1

Type of Ceiling of building1

Type of Top floor of building1

Type of Windows of building1

Type of Ext. Walls of building2

Type of Ceiling of building2

Type of Top floor of building2

Type of Windows of building2

Type of Ext. Walls of building3

Type of Ceiling of building3

Type of Top floor of building3

Type of Windows of building3

\begin{tabular}{|c|}
\hline 12 \\
\hline 1 \\
\hline 17 \\
\hline 6 \\
\hline 8 \\
\hline 0 \\
\hline 11 \\
\hline 1 \\
\hline 19 \\
\hline 0 \\
\hline 26 \\
\hline 3 \\
\hline
\end{tabular}

Type of operation

\begin{tabular}{|c|}
\hline 2 \\
\hline 1 \\
\hline 8 \\
\hline 10 \\
\hline 6 \\
\hline 0 \\
\hline 7 \\
\hline 3 \\
\hline 5 \\
\hline 0 \\
\hline 4 \\
\hline 9 \\
\hline
\end{tabular}

Phase for Ext. Walls of building1

Phase for Ceiling of building1

Phase for Top floor of building1

Phase for Windows of building1

Phase for Ext. Walls of building2

Phase for Ceiling of building2

Phase for Top floor of building2

Phase for Windows of building2

Phase for Ext. Walls of building3

Phase for Ceiling of building3

Phase for Top floor of building3

Phase for Windows of building3

Figure 3: Chromosomes setup for the optimization

\section{4}

\subsubsection{Implementation of phasing}

Phasing is meant here as a generalisation of sequencing. The main difference is that multiple retrofit actions may be carried out the same year. Here, the available yearly budget sets the limit to the yearly number of possible retrofit actions. Technically, it has been done by adding a phasing chromosome to the sequencing chromosome, as shown in Figure 4.

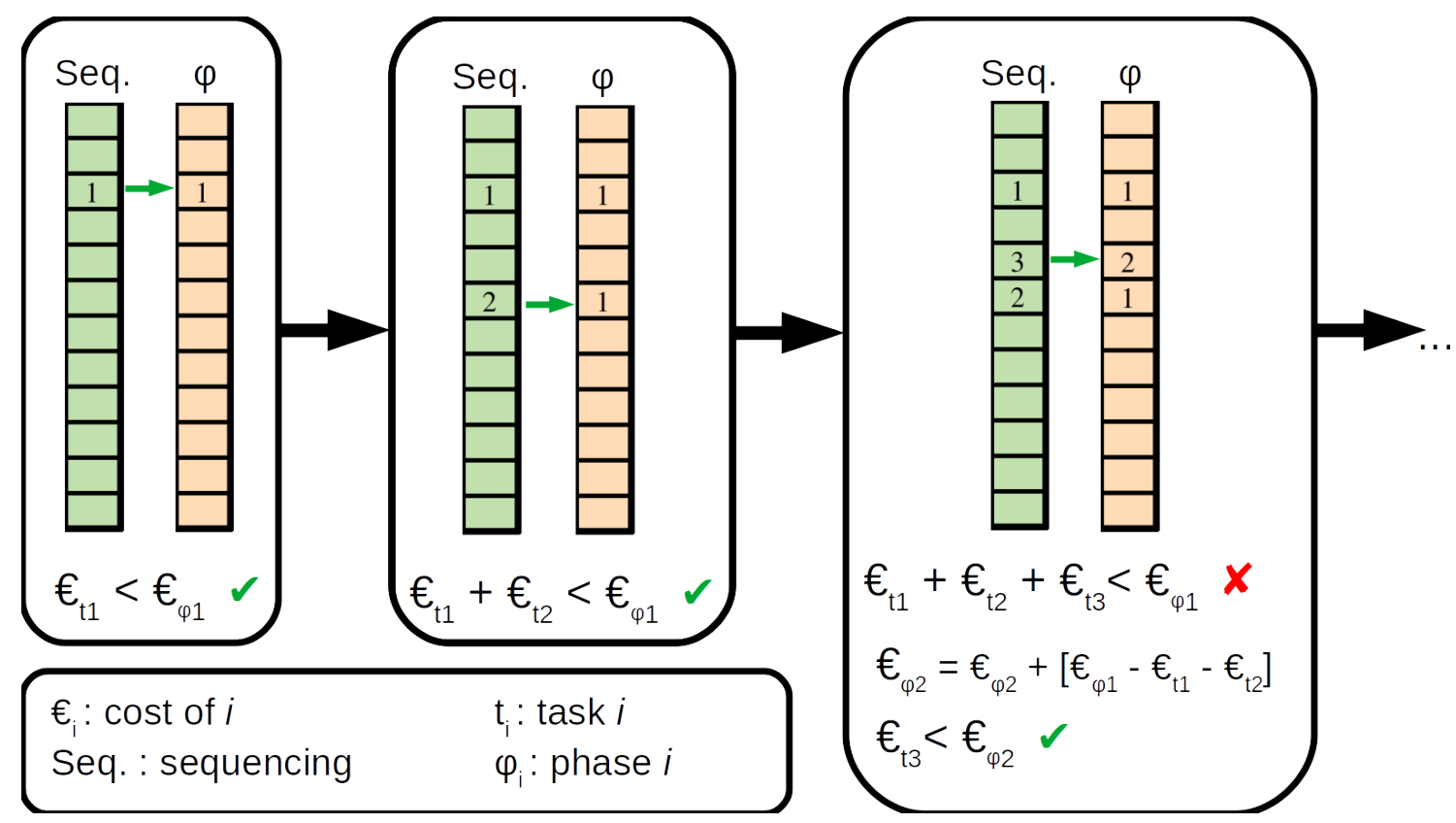

Figure 4: Creation of phasing chromosome 


\subsection{Summary of the optimization scenarios}

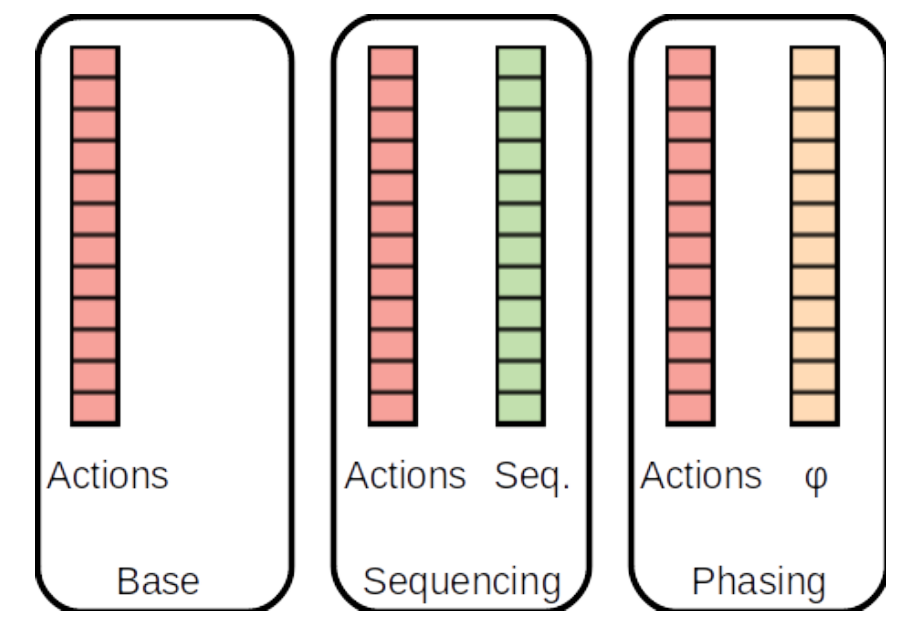

Figure 5: Summary of optimization scenarios is affected to a phase with respect to their order and the available budget by phase. may be affected.

For each individual of the optimization, the cost of each retrofit task is evaluated. Next, each retrofit task

Retrofit actions exceeding the budget are not applied on the building stock, and not evaluated. If an individual has a lot of non-applied actions due to budget limits, the convergence speed of the optimization

In summary, 3 optimization scenarios, listed on Figure 5, will be compared. The base scenario does not include a temporal chromosome and only optimizes the retrofit actions carried out on the building stock. The sequenced optimization uses the chromosome for the retrofit actions as well as the sequencing chromosome. Finally, phased optimization uses the retrofit actions chromosome and the phasing chromosome which elaboration is detailed in Figure 4.

\section{Case Study}

\subsection{Building stock}

Proposed optimization scenarios are applied here on a social housing stock located close to Paris, France. The investigated building stock is composed of 3 apartment blocks, chosen as representative of the whole 
building stock. The specifications of these buildings have been provided by the property manager.

Table 1: Initial characteristics of the buildings.

\begin{tabular}{|c|c|c|c|}
\hline & Building 1 & Building 2 & Building 3 \\
\hline Total floor area & $3020 \mathrm{~m}^{2}$ & $850 \mathrm{~m}^{2}$ & $6667 \mathrm{~m}^{2}$ \\
\hline Shape & Low-rise & High-rise & Low-rise \\
\hline Energy label & $\mathrm{D}\left(151-230 \mathrm{kWh} / \mathrm{m}^{2} /\right.$ year $)$ & $\mathrm{E}\left(231-330 \mathrm{kWh} / \mathrm{m}^{2} /\right.$ year $)$ & $\mathrm{D}$ \\
\hline Number of floors & 5 & 9 & 5 \\
\hline Year of construction & $<1979$ & $<1979$ & $<1979$ \\
\hline Window to wall ratio & $27 \%$ & $24 \%$ & $14 \%$ \\
\hline R-Value walls $\left(\mathrm{m}^{2} . \mathrm{K} / \mathrm{W}\right)$ & 1.25 & 1.25 & 3.1 \\
\hline U window $\left(\mathrm{W} / \mathrm{m}^{2} . \mathrm{K}\right)$ & 2.4 & 2.4 & 2.6 \\
\hline
\end{tabular}

Buildings were modeled in EnergyPlus using Design Builder for the geometry. Their characteristics are listed in Tab. 1. They are initially poorly or not insulated, and have never been renovated before.Building models are detailed in the following section.

\subsection{EnergyPlus modeling and settings}

The choice of EnergyPlus algorithm and parameters reflects the needs of the optimization and the need to describe accurately the buildings: having comparable values for the overheating and heating needs criteria. Consequently the shadowing calculation is kept to the minimum, and no reflections for the radiation were computed. Moreover, convection algorithm were kept to simple indoor and outdoor heat transfer coefficients. According to the EnergyPlus documentation, these settings have a low impact (less than $1.5 \%$ difference) on all output criteria. Used timestep is $30 \mathrm{~min}$.

\subsubsection{Schedules}

Occupation and heating schedules are selected to allow a practical comparison between retrofit strategies. Standard schedules from the French Thermal Regulation are selected ([23]). An example is shown by Tab. 2 .

Table 2: Temperature heating setpoint from [23]

\begin{tabular}{|c|ccc|}
\hline & $\begin{array}{c}\text { Mon-Fri } \\
\text { (except Wed) }\end{array}$ & Wednesday & Weekend \\
\hline 00:00-09:00 & $19^{\circ} \mathrm{C}$ & $19^{\circ} \mathrm{C}$ & $19^{\circ} \mathrm{C}$ \\
09:00-14:00 & $16^{\circ} \mathrm{C}$ & $16^{\circ} \mathrm{C}$ & $19^{\circ} \mathrm{C}$ \\
14:00-18:00 & $16^{\circ} \mathrm{C}$ & $19^{\circ} \mathrm{C}$ & $19^{\circ} \mathrm{C}$ \\
18:00-00:00 & $19^{\circ} \mathrm{C}$ & $19^{\circ} \mathrm{C}$ & $19^{\circ} \mathrm{C}$ \\
\hline
\end{tabular}


Old apartment blocks like those buildings are often naturally ventilated, and although the absence of mechanical ventilation is easy to model, past studies showed that in this case the occupant behavior had a great impact on the ventilation rate $([24,25])$. Indeed, natural ventilation through the window openings has a major influence on the overheating indicator calculated at each evaluation of the model. The model for windows opening proposed by [25] accounts for indoor and outdoor temperatures, but adds a large computational cost to each evaluation. We have therefore chosen a simple assumption. As all buildings are located in a quiet area, the model includes the following natural ventilation rule: If $T_{\text {indoor }}>26^{\circ} \mathrm{C}$ and $T_{\text {indoor }}>T_{\text {outdoor }}$ then tenants are opening windows in order to facilitate natural ventilation.

Air tightness has been modeled with a constant air flow equal to $0.7 \mathrm{vol} / \mathrm{h}$. This is an observed measurement in old collective housing buildings [26].

\subsubsection{Zoning}

Zoning of the building is kept to the minimum of zones in order to speed up calculation while having an acceptable accuracy on simulation results. On such simple building shapes, it has been shown that a limited amount of zones is enough to have accurate results for the heating demand [27]. Consequently we chose to split each building in 7 zones:

- 2 zones for the ground floor: one south, one north

- 2 zones for the top floor: one south, one north

- 2 zones for other floors: one north, one south

- 1 zone for not heated spaces such has stairs and circulations.

An illustration of this zoning is given Figure 6

\subsubsection{Weather}

The weather file selected in a typical reference year (TRY) of Trappes (France). This TRY files has been generated with Meteonorm software with data from the GEBA (Global Energy Balance Archive), from the World Meteorological Organization (WMO/OMM) Climato-logical Normals 1961-1990. It is the weather file used as reference is the French Thermal Regulation [23]. The weather data are used for all of the 20 years of evaluation. 


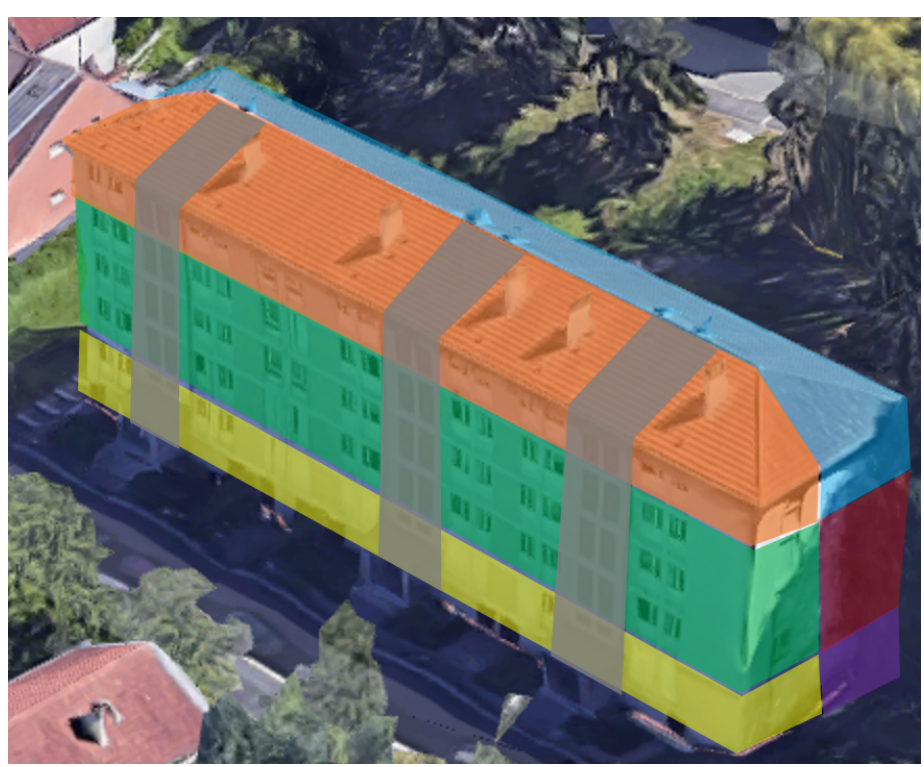

Figure 6: Building 1 with its zoning: each color represent a thermal zone. Grey is for unheated spaces such as stairs an circulation

\subsection{Response of the model}

First, annual heating needs and the overheating criteria were computed. They are shown in Table 3. Buildings Table 3: Simulated characteristics of the buildings before retrofit

\begin{tabular}{|c|ccc|}
\hline & Building 1 & Building 2 & Building 3 \\
\hline Heating needs & $146 \mathrm{kWh} / \mathrm{m}^{2}$ & $228 \mathrm{kWh} / \mathrm{m}^{2}$ & $191 \mathrm{kWh} / \mathrm{m}^{2}$ \\
Overheating & $297{ }^{\circ} \mathrm{C} . \mathrm{h} / \mathrm{m}^{2}$ & $180{ }^{\circ} \mathrm{C} . \mathrm{h} / \mathrm{m}^{2}$ & $306{ }^{\circ} \mathrm{C} . \mathrm{h} / \mathrm{m}^{2}$ \\
\hline
\end{tabular}

227

- Air temperature of a south oriented zone

- Air temperature of a north oriented zone

- Outdoor air temperature

- Direct horizontal solar radiation 
As shown in Figure $7 \mathrm{a}$, the south zone reaches more than $35^{\circ} \mathrm{C}$. This is due to the fact that during the day, the occupants are scheduled to be out of their apartment, therefore they can not open the window to ventilate. Moreover, the building has no insulation and a fair amount of windows without solar shadings $(27 \%)$ which ensures a quick rise of temperature on days with high solar radiation. It can be noted that as soon as occupants come back home, the temperature drops dramatically because of the windows' opening, modelled as stated in section 3.2.1.

In winter (Figure $7 \mathrm{~b}$ ), the model reaches the setpoint temperature flawlessly as the heater is modelled as an ideal heating system. It is striking to realize that the building has low inertia therefore drops quickly to the low temperature setpoints each day. It can also be noted that the building is sensitive to solar gain even in winter, thanks to its large windows area.

The same analysis can be made with the other buildings which share the same typology as this one.

\subsection{Parameters of the model to optimize}

The present case study focuses on the retrofit of the building envelope. For each of the three buildings, we optimized vertical walls, ceilings and floors as well as windows. Each of these variables to optimize is a parameter of the model. There are three buildings with 4 parameters to optimize on each one, hence 12 parameters which are listed as parts of the chromosome Type of operation in Figure 3.

\subsection{Decision space}

The decision space is the set of possible parameter values of the model to be optimized. The parameters can be broken down into two types:

- Window properties: genes 4, 8, 12 of the pictured chromosome as shown in Figure 3.

- Wall properties (vertical walls, floors and ceilings): all other genes.

For the windows parameters, the decision space is defined by the possible $\mathrm{U}$-values, solar factor and visible transmittance that may be applied to all windows of a building.Possible values, taken from a manufacturer catalogue, are: 
Table 4: Description of the decision space for windows

\begin{tabular}{|c|c|c|c|c|c|}
\hline $\mathrm{U}_{w}$ values $\left(\mathrm{W} / \mathrm{m}^{2} . \mathrm{K}\right)$ & 0.8 & 1 & 1.2 & 1.4 & 2.0 \\
\hline Solar factor & 0.76 & 0.73 & 0.67 & 0.64 & 0.61 \\
\hline Visible Transmittance & 0.81 & 0.83 & 0.86 & 0.88 & 0.9 \\
\hline
\end{tabular}

For walls, the decision space covers different insulation materials. Each material may replace the current insulation of the wall, which is external on all of the three buildings. Possible materials are:

Table 5: Description of the decision space for walls

\begin{tabular}{|c|c|}
\hline Materials & Thicknesses $(\mathrm{cm})$ \\
\hline Glasswool $\left(\lambda=0.04 \mathrm{~W} / \mathrm{m}^{2} . \mathrm{K}\right)$ & $2,4,6,8,10,12,14,16,18,20$ \\
\hline Rockwool $\left(\lambda=0.042 \mathrm{~W} / \mathrm{m}^{2} . \mathrm{K}\right)$ & $2,4,6,8,10,12,14,16,18,20$ \\
\hline Polystyrene $\left(\lambda=0.032 \mathrm{~W} / \mathrm{m}^{2} . \mathrm{K}\right)$ & $2,4,6,8,10,12,14,16,18,20$ \\
\hline Polyurethane $\left(\lambda=0.03 \mathrm{~W} / \mathrm{m}^{2} . \mathrm{K}\right)$ & $2,4,6,8,10,12,14,16,18,20$ \\
\hline
\end{tabular}

Each of these materials has its own thermal properties and its price is computed according to expert knowledge provided by engineering companies. The price can be split in two parts: the cost of the material itself, that depends on the thickness and the type of the material, and the price of the construction that depends only on the material.

\subsection{Hyperparameters of the algorithm}

The NSGA2 algorithm has 3 main hyperparameters to be set: the number of individuals, number of generations and crossover probability. [28] and [16] state that convergence was reached in genetic algorithm optimization on 12 parameters with 30 individuals and 10 generations with a crossover probability in the range $[0.8 ; 1]$. After checking the convergence and the repeatability of the optimisation for multiple hyperparameters, the following parameters are chosen:

Table 6: Hyperparameters of NSGA2 for our case study

\begin{tabular}{|cc|}
\hline Number of individuals & 96 \\
Number of generations & 100 \\
Crossover probability & 0.8 \\
Mutation probability & 0.2 \\
\hline
\end{tabular}

The validity of these parameters is checked after the optimization through hypervolume monitoring and qualitative evaluation of convergence. 


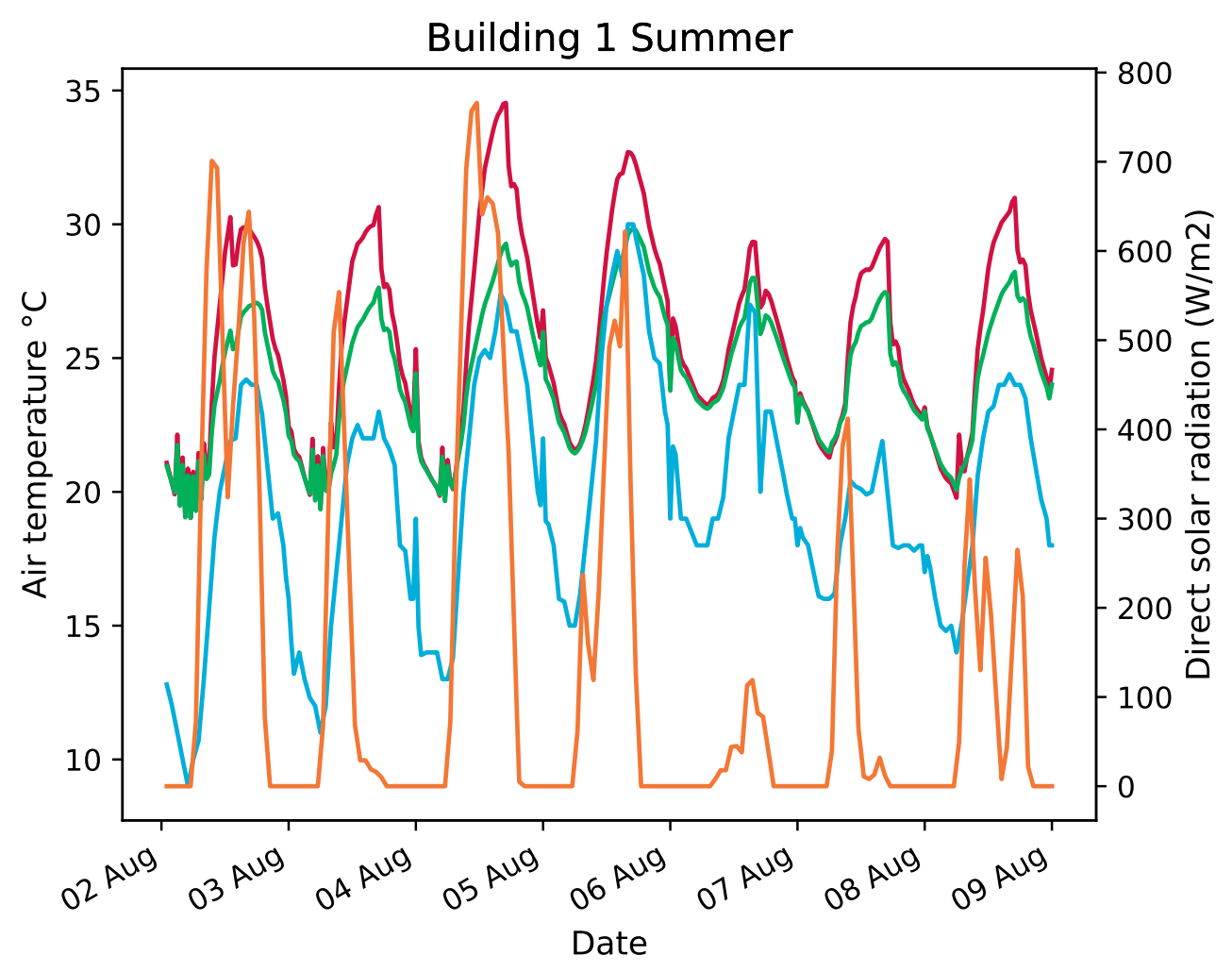

(a) Summer week for Building 1

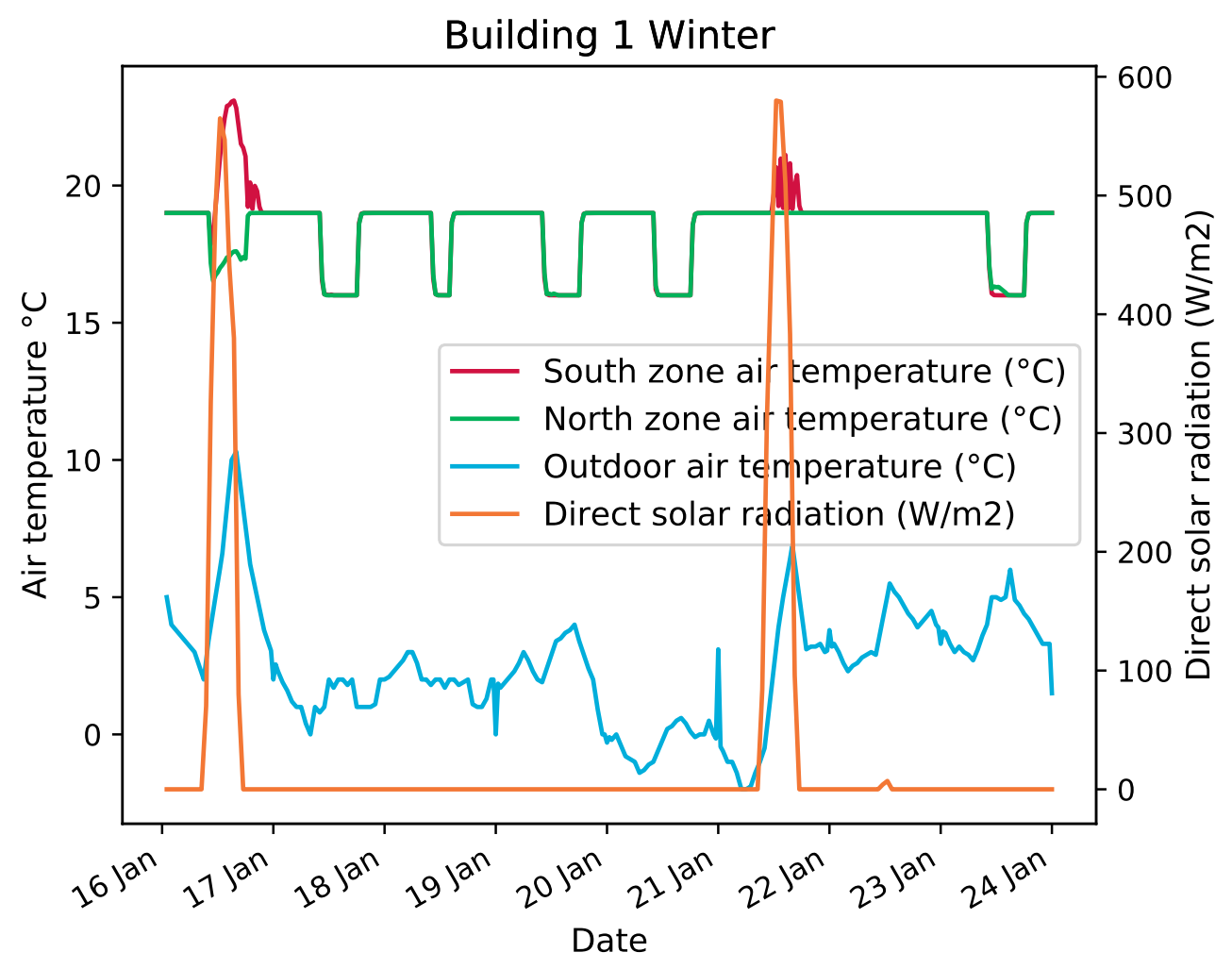

(b) Winter week for Building 1

Figure 7: Building 1 


\section{Results}

First of all, the global behavior of the optimization will be verified. Then we will compare the optimal strategies given by the optimization with base, sequencing or phasing.

\subsection{Pareto front at the end of the optimization : overview}

On Figure 8, the Pareto fronts of the optimal retrofit strategies are compared. The first one concerns the base optimization, which includes no temporality effect. The second one is the sequenced optimization, where one retrofit task is proposed per year. The third one is the phased optimization which enables multiple tasks to be carried on the same year.

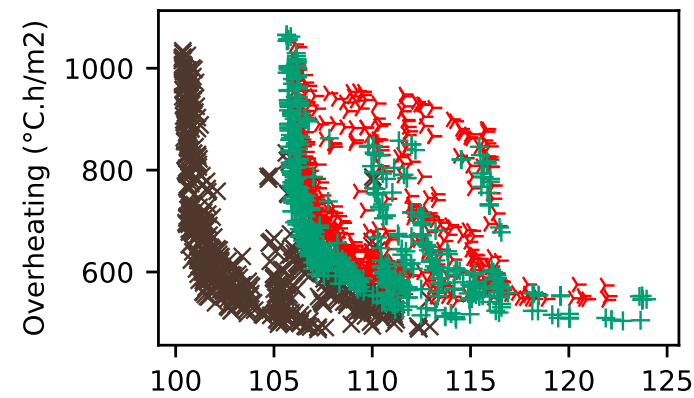

$\times$ Base

$\checkmark$ Sequencing

+ Phasing
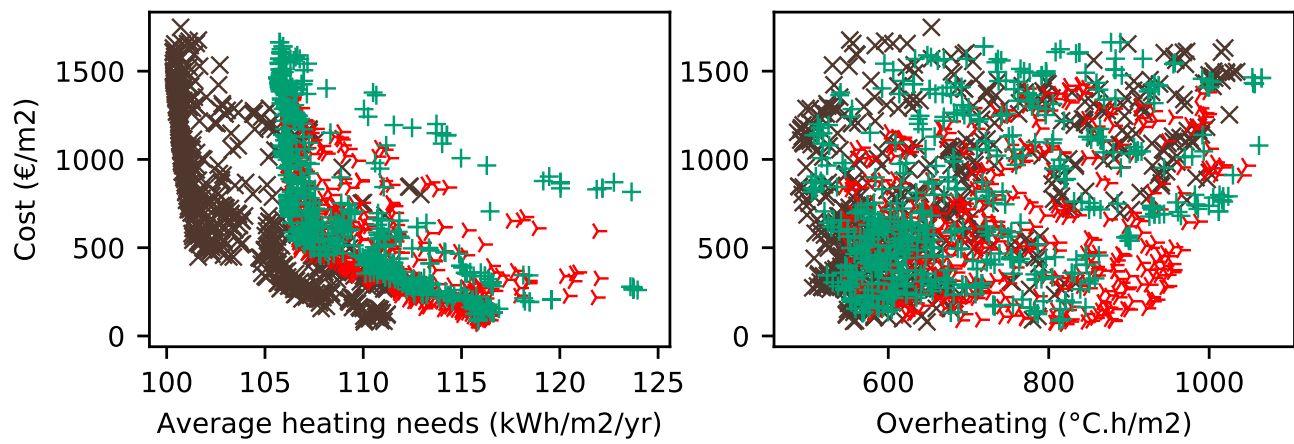

Figure 8: Pareto front comparison of based, sequenced and phased optimization int ob (1)

In each subplot of Figure 8, we can see individuals that are "dominated" if we take only two objectives into account. It can be noticed on Figure 9: as the individuals perform less on the cost and heating needs objective, they perform better on the overheating objective. This behavior is expected in a multi-objective optimization and enables the verification of the implementation of the algorithm for our problem.

The three Pareto fronts are different and this difference can be explained by the formulation of the 


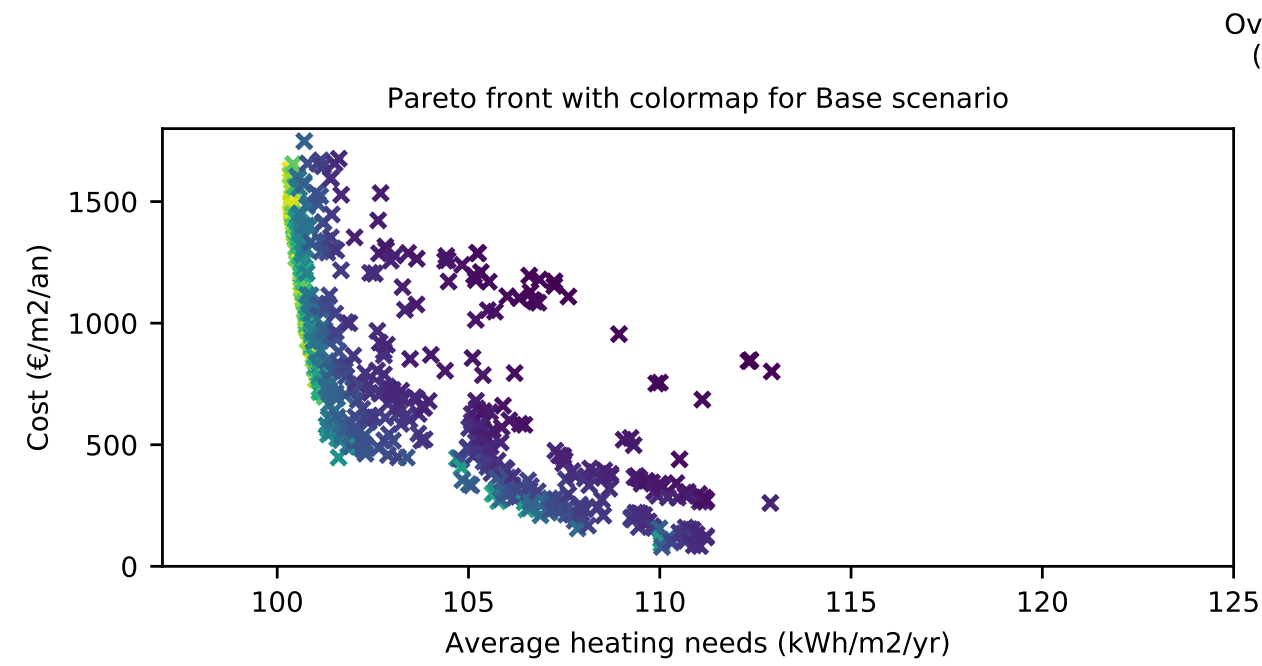

Overheating

$\left({ }^{\circ} \mathrm{C} . \mathrm{h} / \mathrm{m} 2\right)$
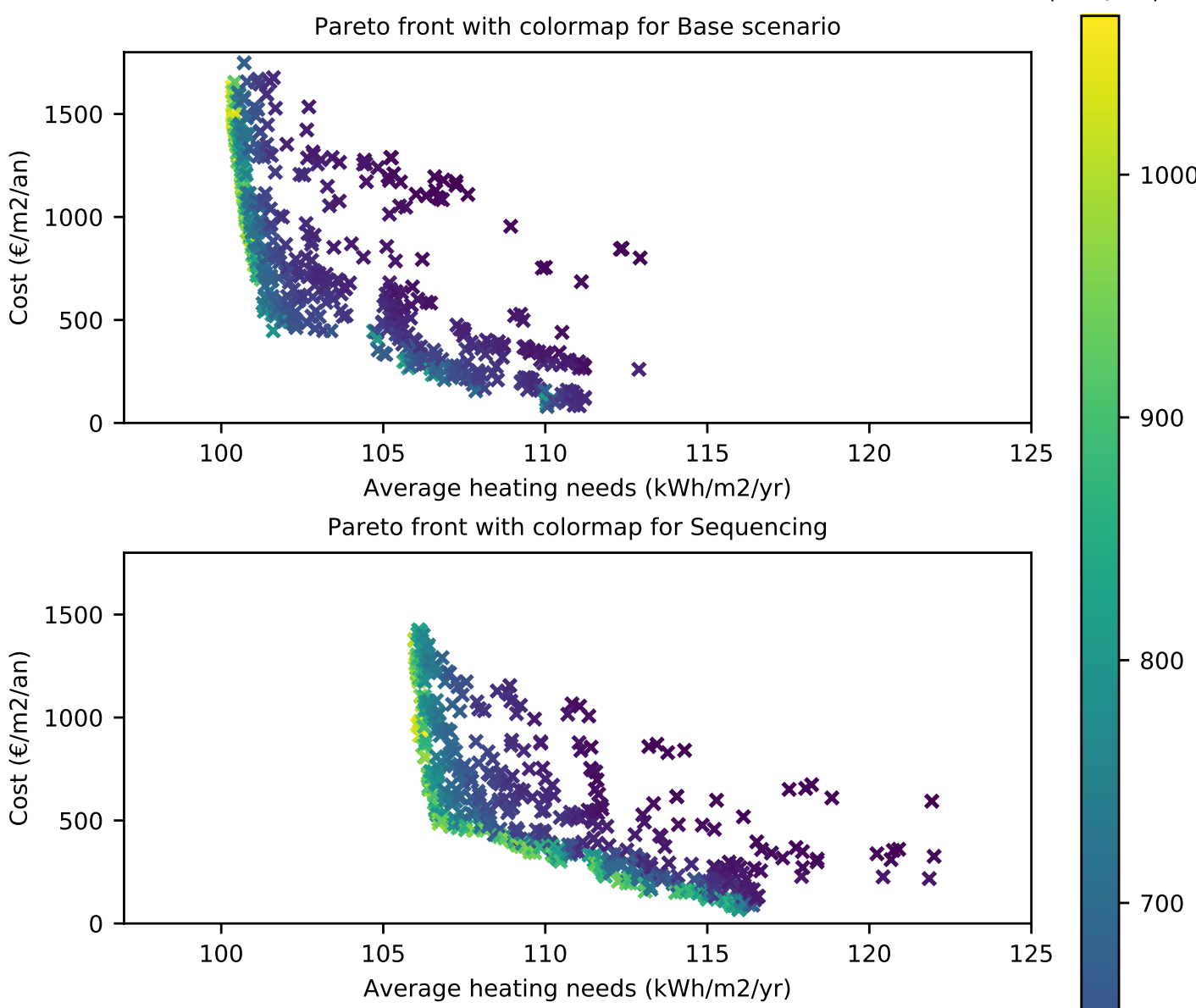

Pareto front with colormap for Phasing

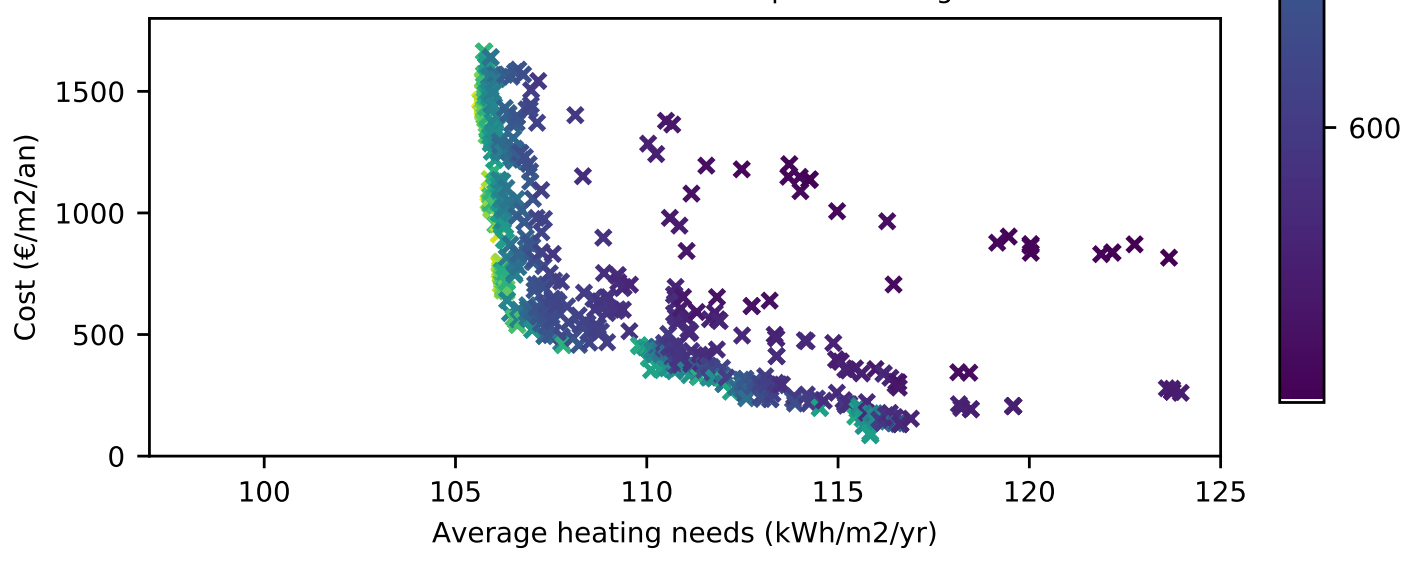

Figure 9: Comparison of optimal retrofit strategies 
problem. Indeed, in Figure 8, the best performances seem to be achieved by the base optimization, then the phasing optimization and finally the sequenced optimization. This is due to the fact that in the base scenario, all of the retrofit actions are done at the very beginning, from the first year. In the sequenced optimization, the retrofit actions are spread over 12 years and in the phasing optimization over 4 years. As the evaluation has been carried out on 20 years, this implies that the amount of years where the building has a poor performance is the longest for the sequenced optimization, which explains its lower performance compared to the two other scenarios.

Additional discussions will be proposed in section 4.2.2.

\subsection{Global behavior of the optimization and convergence}

First of all, convergence of the optimization has to be checked, and the hypervolume and its evolution is a meaningful criteria to do so [29]. Figure 10 shows the evolution of the hypervolumes along generations for base, sequenced and phased optimization. Hypervolume progression shows a convergence of phased and sequenced optimisation towards the Pareto front that is obtained with based optimisation. However, the gap of hypervolume values at generation 83 for phased optimization could question the convergence of the optimization, but small variability of hypervolumes between the 3 fronts at generation 100 increase the confidence in the convergence of this optimization. The gap at generation 83 is due to the progression of the Pareto front on the overheating objective for solutions that cost between 1100 and $1250 € / \mathrm{m}^{2}$, the evolution on other criterias is not significant.

\subsubsection{Interpretation of the results}

The content of the retrofit strategies shows an overall difference between strategies from the base optimization and phased strategies. The main differences lie in the retrofit of the windows and in the thickness of the proposed insulation.

First of all observations, the higher the cost of the retrofit strategies, the more windows are treated: cheapest strategies do not retrofit any windows, strategies a bit more costly retrofit windows on one building, etc... This can be shown on Tables 7 and 8. Theses tables split the Pareto front in 8 clusters depending on how which building gets its windows retrofitted. In the first three columns of this table is detailed whether the windows get retrofitted for every building: if the building's windows are treated, the value in this column is " 1 ". In the following columns, the mean values and the standard deviation for each objective function are 


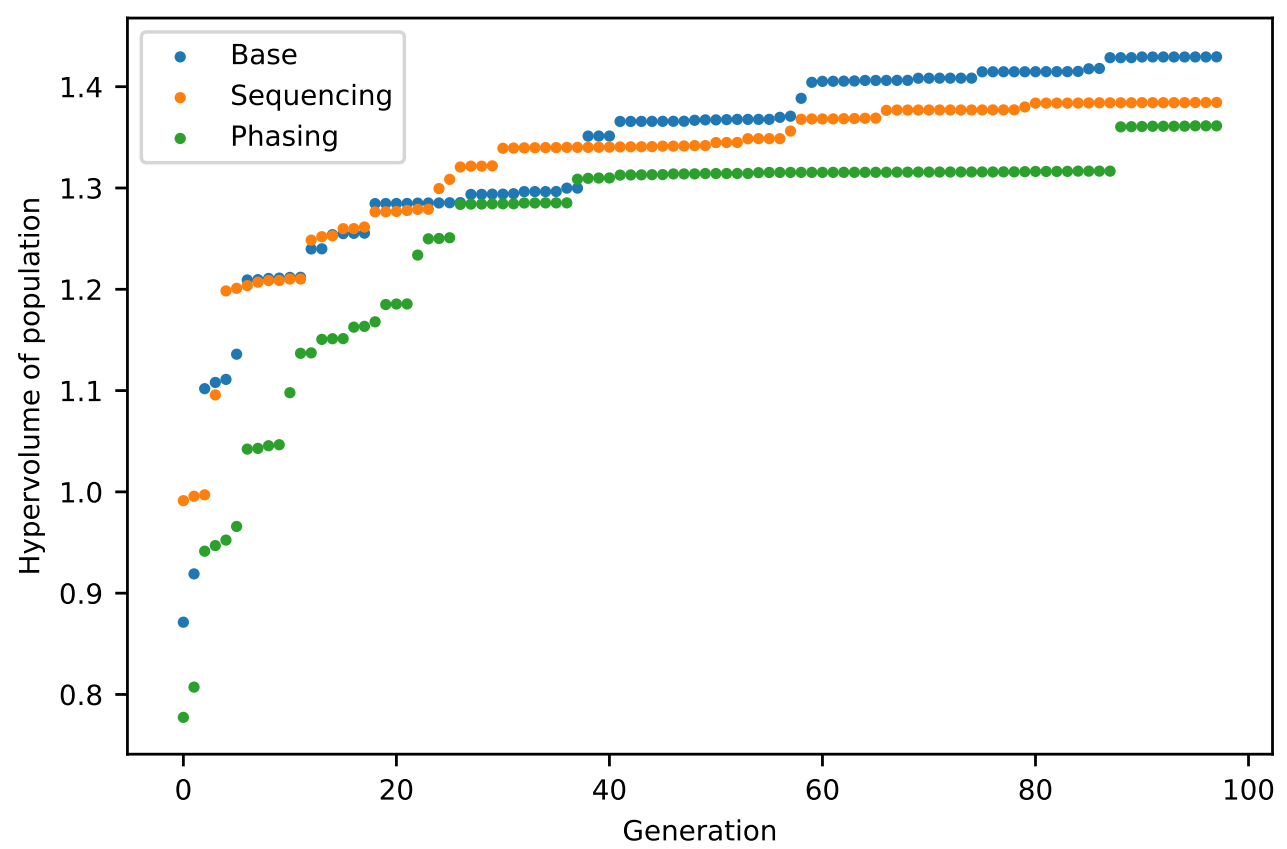

Figure 10: Hypervolume of Pareto front along generations

detailed for each cluster.

Figures 11 and 12 are using the same coding of Tables 7 and 8 to describe the retrofit of windows, which is detailed in the previous paragraph.

We can see a difference between in which building is treated when not all buildings are retrofitted. In the phased optimization, windows from Building 3 are treated first, then Building 1. In base optimization, windows from Building 1 are retrofitted first, then windows from Building 3. For bot of the optimization, windows from Building 2 are retrofitted in last.

On Figures 11 and 12, few differences are visible about the distribution of the solutions. However, in the phased optimisation, the transition between the solutions that are retrofitting the windows of Building 3 and the solutions retrofitting the windows of Building 1 and Building 3 is more clear and occurs at a lower cost than in the base optimization. This is confirmed by the datas from Tables 7 and 8 . As the only differences between both of the optimizations are the integration of the temporality and the integration of a maximal cost of retrofit, and the fact that the concerned solutions are costing 600 to $700 € / \mathrm{m}^{2}$, this observation can be accounted on the integration of temporality. 
Table 7: Mean and standard deviation of solutions function of retrofitted windows: base optimization

\begin{tabular}{|c|c|c|c|c|c|c|c|c|}
\hline \multicolumn{3}{|c|}{ Windows } & \multicolumn{2}{c|}{ Heating needs $(\mathrm{kWh} / \mathrm{m} 2 . \mathrm{yr})$} & \multicolumn{2}{c|}{ Overheating $\left({ }^{\circ} \mathrm{C} . \mathrm{h} / \mathrm{m} 2 . \mathrm{yr}\right)$} & \multicolumn{2}{c|}{ Cost $€ / \mathrm{m} 2 . \mathrm{yr}$} \\
\hline $\begin{array}{c}\text { Building } \\
1\end{array}$ & $\begin{array}{c}\text { Building } \\
2\end{array}$ & $\begin{array}{c}\text { Building } \\
3\end{array}$ & Mean & $\begin{array}{c}\text { Standard } \\
\text { Deviation }\end{array}$ & Mean & $\begin{array}{c}\text { Standard } \\
\text { Deviation }\end{array}$ & Mean & $\begin{array}{c}\text { Standard } \\
\text { Deviation }\end{array}$ \\
\hline 0 & 0 & 0 & 108.6 & 1.9 & 603 & 45 & 219 & 69 \\
\hline 0 & 0 & 1 & 102.7 & 1.6 & 650 & 70 & 600 & 170 \\
\hline 0 & 1 & 0 & N/A & N/A & N/A & N/A & N/A & N/A \\
\hline 0 & 1 & 1 & 101 & 0.1 & 743 & 66 & 1206 & 113 \\
\hline 1 & 0 & 0 & 109 & 1.3 & 537 & 19 & 361 & 57 \\
\hline 1 & 0 & 1 & 102 & 1.7 & 711 & 192 & 882 & 208 \\
\hline 1 & 1 & 0 & 111 & 1.8 & 495 & 2.7 & 828 & 94 \\
\hline 1 & 1 & 1 & 102 & 1.9 & 748 & 196 & 1400 & 166 \\
\hline \multicolumn{8}{|c|}{$\begin{array}{c}\text { N/A: no retrofit strategies for this case } \\
\text { 0: windows retrofitted on this building }\end{array}$} \\
\end{tabular}

For both optimizations, it is sensible to retrofit windows Building 1 and Building 3 first as their windowto-wall ratio is higher than Building 2 (0,27 for Building 1 and 0,23 for Building 3, only 0,16 for Building 2)

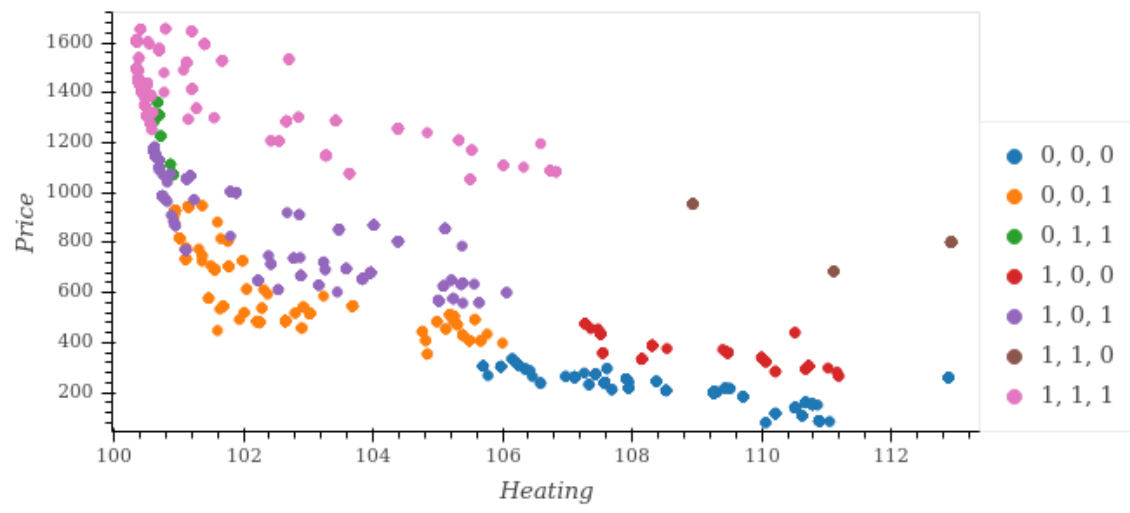

Figure 11: Individual from Pareto front function of retrofitted windows: base optimization

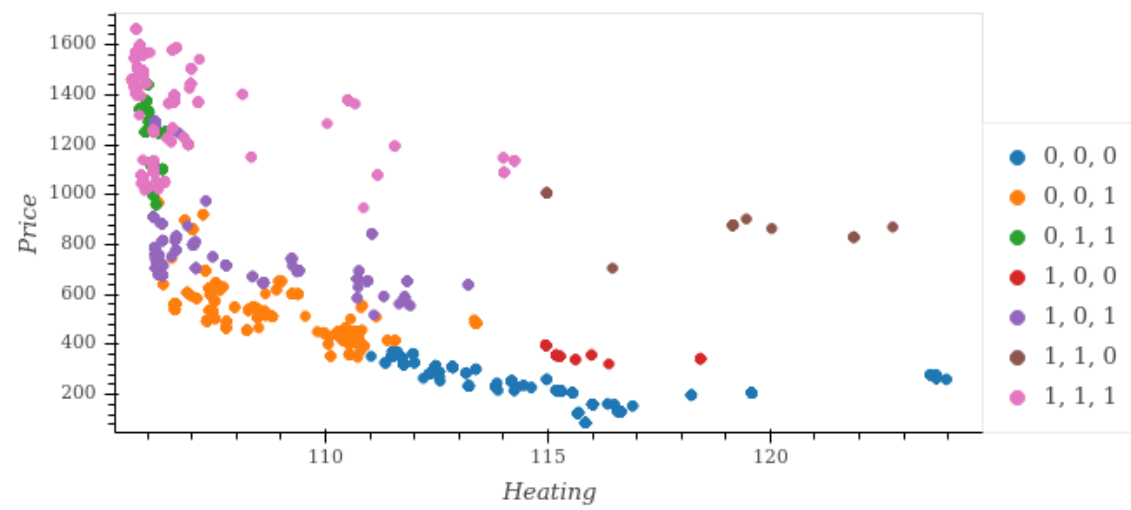

Figure 12: Individual from Pareto front function of retrofitted windows: phased optimization 
Table 8: Mean and standard deviation of solutions function of retrofitted windows: phased optimization

\begin{tabular}{|c|c|c|c|c|c|c|c|c|}
\hline \multicolumn{3}{|c|}{ Windows } & \multicolumn{2}{c|}{ Heating needs } & \multicolumn{2}{c|}{ Overheating } & \multicolumn{2}{c|}{ Cost } \\
\hline $\begin{array}{c}\text { Building } \\
1\end{array}$ & $\begin{array}{c}\text { Building } \\
2\end{array}$ & $\begin{array}{c}\text { Building } \\
\text { 3 }\end{array}$ & Moyenne & $\begin{array}{c}\text { Standard } \\
\text { Deviation }\end{array}$ & Mean & $\begin{array}{c}\text { Standard } \\
\text { Deviation }\end{array}$ & Mean & $\begin{array}{c}\text { Standard } \\
\text { Deviation }\end{array}$ \\
\hline 0 & 0 & 0 & 115 & 3.4 & 656 & 85 & 249 & 71 \\
\hline 0 & 0 & 1 & 109 & 1.9 & 663 & 86 & 531 & 119 \\
\hline 0 & 1 & 0 & N/A & N/A & N/A & N/A & N/A & N/A \\
\hline 0 & 1 & 1 & 106 & 0.2 & 794 & 56 & 1257 & 124 \\
\hline 1 & 0 & 0 & 116 & 1.2 & 547 & 12 & 365 & 24 \\
\hline 1 & 0 & 1 & 107 & 1.8 & 778 & 170 & 774 & 164 \\
\hline 1 & 1 & 0 & 119 & 2.6 & 514 & 4.2 & 886 & 79 \\
\hline 1 & 1 & 1 & 107 & 1.8 & 775 & 149 & 1315 & 194 \\
\hline \multicolumn{8}{|c|}{$\begin{array}{c}\text { N/A: no retrofit strategies for this case } \\
\text { 1: windows retrofitted on this building }\end{array}$} \\
\hline
\end{tabular}

With the same data-exploration methods, we focused the analysis on insulation thickness. Even if thermal conductivities of insulations are different, it is a fair approximation of the global behavior of the optimization. We noticed that insulation proposed on phased optimization tend to be thicker than proposed insulation on base optimization. This is due to the fact that retrofit actions are limited by the budget in the case of phased optimization, thus the algorithm proposes solutions where less walls are retrofitted, but with a higher insulation.

For both of the optimization, we can notice that optimal retrofit solutions tend to insulate the largest parts of the buildings more. For example, optimal strategies for the high-rise building features a good insulation $(R>3 \mathrm{~K} / \mathrm{W})$ on vertical walls whereas the thermal resistance of ceilings and floors can be as low as $R=1,7$ $\mathrm{K} / \mathrm{W}$ in some optimal strategies. Similarly, optimal strategies for Building 1 tend prioritize the insulation of roofs and ceilings over walls. This is due to the fact that this building is low-rise and features a greater amount of windows on vertical walls ( $27 \%$ of vertical surface).

Finally, we can conclude that the content of the optimal retrofit strategies does change with the integration of temporality. The same conclusion can be drawn for sequenced and phased optimization, and that increase the confidence we have in the result of the optimizations even with the convergence difference shown in section 4.2. Moreover, the fact that the differences between optimal strategies proposed for base and phased optimization can be explained is increasing our confidence into the results. 

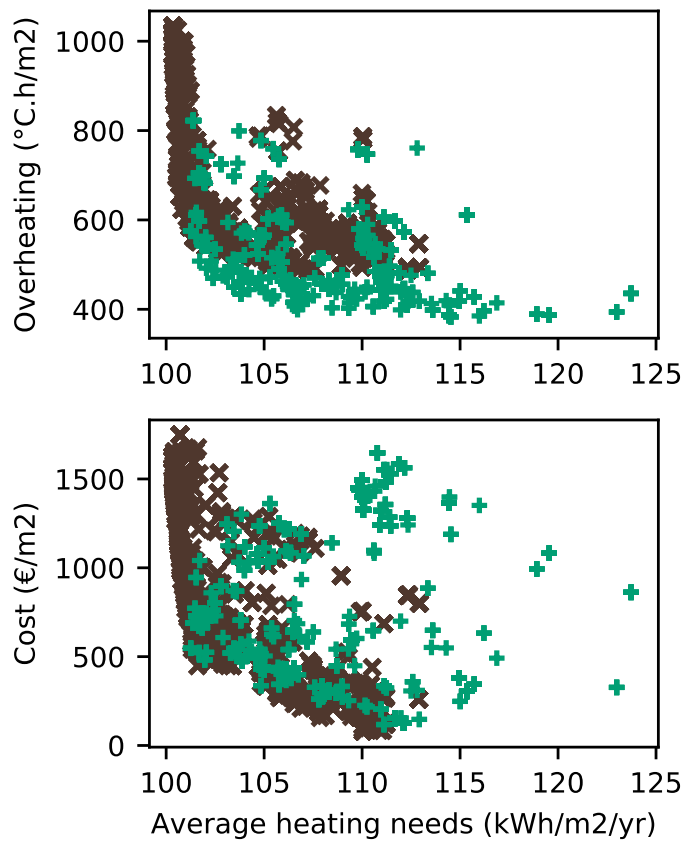

\subsubsection{Utility of the integration of phasing}

Originally, the motivation for the integration of phasing is to get closer to real world practice. The integration of phasing was done in the optimization and gave sensible results, in accordance with the base optimization and with real world figures. The question is now whether the integration of phasing proposes different solutions than the base optimization. In order to compare strategies proposed in the base and phased optimization, we plotted the performance of the building on its final state, i.e. on the last year of the 20 years period considered for the evaluation of the performance. This plot is available on Figure 13.

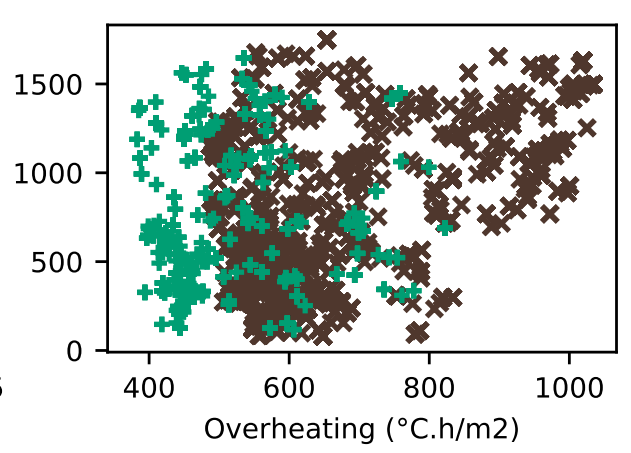

Figure 13: Comparison of final state of optimal retrofit

First of all, Figure 13 show that final states of phased optimal strategies have not the same performance than optimal strategies generated in base optimization. Indeed, retrofit strategies on Pareto front for phased optimization have in average a better performance on overheating objective and have in average a worse performance on the cost and heating needs. Moreover, as stated in Section 4.2.1, strategies differ between base and phased optimization mainly concerning the choice of windows to be retrofitted. This implies that the implementation of phasing in the optimization results in different optimal strategies than those proposed by the base version of the optimization. 


\subsection{Benefits and limitations}

In the literature, sequenced optimization of energy retrofit started to be taken into account [14] but was limited to one retrofit action per year. The real world practice in construction is to break down a major retrofit operation in small phases containing multiple retrofit actions per year: the method aims to replicate this practice.

The proposed method enables the elaboration of optimized retrofit strategies for a small building stock and includes a temporal dimension in each strategy, in order to describe how the retrofit action should be planned. Results show a small improvement between the performance of the proposed strategies when compared to an optimization without phasing. The main result is that proposed strategies differ when the optimization is carried out with phasing.

The major implication of this finding is that optimal strategies depend on how the problem is formulated compared to the reality of retrofit actions: the closer the optimization process to the constraints of the property manager, the more relevant the results will be .

Limitations of the work relates to two main areas. First of all, the cost criteria could be improved by accounting inflation, or by optimizing the life-cycle cost of the building, as proposed by Milic et al. [30]. This would bring a new economy metric to the decision maker, although the construction cost would remain a strong constraint for the realization of the retrofit work.

Secondly, the optimization algorithm, NSGA-II, is suitable for our problem with 12 parameters and 3 objective functions $[31,32]$. Some limitations have however been found on the quality of the Pareto front generated which can be improved by NSGA-III [33], especially on constrained optimization.

\section{Conclusion}

A method is proposed for the elaboration of optimal retrofit strategies of building stocks, including the planning of retrofit actions over time. We applied this method on a small building stock of three buildings as a test case.

The major finding is that integrating the temporal aspect of operations into the optimization leads to different optimal strategies. The major difference between phased and non-phased strategies is illustrated with the order of windows retrofit along the buildings of the stock. This difference is illustrated on Figure 9, 
as we can see that objective function values are improved on the cost but can not be as good on the heating needs and overheating objective, as explained in Section 4.1. This highlights the importance of formulating the optimization problem as close as possible to the constraints of decision makers, in order to generate realistic and useful optimal strategies.

Once the method proposed in this paper is applied, resulting strategies can then be limited to a few strategies through multicriteria decision aid with the decision maker, in order to account for non-measurable objectives such as politics, feeling of the tenants... This guarantees that the decision maker is part of the process while ensuring that the final decision is optimal.

Considering the importance of the formulation of the problem on the relevance of optimal strategies, further studies can be carried out to evaluate the sensitivity of the problem to different parameters such as climate change or occupant behavior. The variability of the weather can also be investigated as more frequent heatwaves may influence the overheating objective. Lastly, an additional objective function can be optimized as well, such as an environmental objective $\left(\mathrm{CO}_{2}\right.$ emitted by the building along its life cycle and environmental cost of the retrofit).

\section{Acknowledgments}

The authors would like to acknowledge French National Research Agency (ANR) for its funding within ANR-15-CE22-0011 Reha-Parcs project.

\section{References}

[1] International Energy Agency, "Statistics — World - Total Primary Energy Supply (TPES) by source (chart)," 2012.

[2] M. Babiker, P. Bertoldi, M. Buckeridge, A. Cartwright, M. Araos Maldives, S. Bakker, A. Bazaz, E. Belfer, T. Benton, H. de Coninck, A. Revi, M. Babiker, P. Bertoldi, M. Buckeridge, A. Cartwright, W. Dong, J. Ford, S. Fuss, J. Hourcade, D. Ley, R. Mechler, P. Newman, A. Revokatova, S. Schultz, L. Steg, T. Sugiyama, V. Masson-Delmotte, P. Zhai, H. O. Pörtner, D. Roberts, J. Skea, P. Shukla, A. Pirani, W. Moufouma-Okia, C. Péan, R. Pidcock, S. Connors, J. B. R Matthews, Y. Chen, X. Zhou, 
M. I. Gomis, E. Lonnoy, T. Maycock, M. Tignor, and T. Waterfield, "Chapter 4 - Strengthening and Implementing the Global Response," p. 132, 2018.

[3] Programme Rage, Analyse détaillée du parc résidentiel existant. 2017.

[4] N. Kohler and U. Hassler, "The building stock as a research object," Build. Res. Inf., vol. 30, no. 4, pp. 226-236, 2002.

[5] D. Gossard, B. Lartigue, and F. Thellier, "Multi-objective optimization of a building envelope for thermal performance using genetic algorithms and artificial neural network," Energy Build., vol. 67, pp. 253-260, 2013.

[6] K. Mela, T. Tiainen, and M. Heinisuo, "Comparative study of multiple criteria decision making methods for building design," Adv. Eng. Informatics, vol. 26, pp. 716-726, oct 2012.

[7] A. N. Gade, T. S. Larsen, S. B. Nissen, and R. L. Jensen, "REDIS: A value-based decision support tool for renovation of building portfolios," Build. Environ., vol. 142, no. June, pp. 107-118, 2018.

[8] I. Costa-Carrapiço, R. Raslan, and J. N. González, "A systematic review of genetic algorithm-based multi-objective optimisation for building retrofitting strategies towards energy efficiency," Energy Build., vol. $210,2020$.

[9] O. Pasichnyi, F. Levihn, H. Shahrokni, J. Wallin, and O. Kordas, "Data-driven strategic planning of building energy retrofitting: The case of Stockholm," J. Clean. Prod., 2019.

[10] G. Guariso and M. Sangiorgio, "Multi-objective planning of building stock renovation," Energy Policy, vol. 130, no. March, pp. 101-110, 2019.

[11] J. Zhou, P. E. Love, X. Wang, K. L. Teo, and Z. Irani, "A review of methods and algorithms for optimizing construction scheduling," J. Oper. Res. Soc., vol. 64, no. 8, pp. 1091-1105, 2013.

[12] D. N. Grant, J. J. Bommer, R. Pinho, G. M. Calvi, A. Goretti, and F. Meroni, "A prioritization scheme for seismic intervention in school buildings in Italy," Earthq. Spectra, vol. 23, pp. 291-314, may 2007.

[13] F. Taillandier, G. Sauce, and R. Bonetto, "Elaboration of a long-term maintenance plan for building stock based on arbitration using a risk approach," Eur. J. Environ. Civ. Eng., vol. 13, pp. 383-397, apr 2009 .

[14] M. Rivallain, Étude de l'aide à la décision par optimisation multicritère des programmes de réhabilitation énergétique séquentielle des bâtiments existants. PhD thesis, jan 2013. 
[15] ASHRAE, "ANSI/ASHRAE 55-2004: Thermal Environmental Conditions for Human Occupancy," tech. rep., 2004.

[16] R. Evins, "A review of computational optimisation methods applied to sustainable building design," Renew. Sustain. Energy Rev., vol. 22, pp. 230-245, jun 2013.

[17] G. Valkanas, A. N. Papadopoulos, and D. Gunopulos, "Skyline ranking ?? la IR," in CEUR Workshop Proc. (M. Schoenauer, K. Deb, G. Rudolph, X. Yao, E. Lutton, J. J. Merelo, and H.-P. Schwefel, eds.), vol. 1133 of Lecture Notes in Computer Science, pp. 182-187, Springer Berlin Heidelberg, sep 2014.

[18] V. Machairas, A. Tsangrassoulis, and K. Axarli, "Algorithms for optimization of building design: A review," Renew. Sustain. Energy Rev., vol. 31, pp. 101-112, mar 2014.

[19] F.-A. Fortin, F.-M. De Rainville, M.-A. Gardner, M. Parizeau, and C. Gagné, "DEAP : Evolutionary Algorithms Made Easy," J. Mach. Learn. Res., vol. 13, pp. 2171-2175, 2012.

[20] F.-A. Fortin and M. Parizeau, "Revisiting the NSGA-II crowding-distance computation," Proceeding fifteenth Annu. Conf. Genet. Evol. Comput. Conf. - GECCO '13, p. 623, 2013.

[21] V. A. Cicirello and S. F. Smith, "Modeling GA Performance for Control Parameter Optimization 2 Largest Common Subgraph Genetic," 1995.

[22] F.-M. D. D. Rainville, C. Gagné, O. Teytaud, D. Laurendeau, F.-M. D. D. Rainville, C. Gagné, O. Teytaud, and D. L. E. Op, "Evolutionary Optimization of Low-Discrepancy Sequences," ACM Trans. Model. Comput. Simul., vol. 22, pp. 1-25, mar 2012.

[23] CSTB, "Arrêté du 30 avril 2013 portant approbation de la méthode de calcul Th-BCE 2012 prévue aux articles 4, 5 et 6 de l'arrêté du 26 octobre 2010 relatif aux caractéristiques thermiques et aux exigences de performance énergétique des bâtiments nouveaux et des," J. Off., vol. n0106: 77, 2012.

[24] R. Andersen, V. Fabi, J. Toftum, S. P. Corgnati, and B. W. Olesen, "Window opening behaviour modelled from measurements in Danish dwellings," Build. Environ., vol. 69, pp. 101-113, 2013.

[25] F. Haldi and D. Robinson, "Interactions with window openings by office occupants," Build. Environ., vol. 44, no. 12, pp. 2378-2395, 2009.

[26] A. Litvak, K. Guillot, M. Kilberger, and D. Boze, "Airtightness of French dwellings Results from field measurement studies," Proc. 21st AIVC Annu. Conf. "Innovations Vent. Technol. 26-29 Sept. 2000, no. September 2000, pp. 1-12, 2000. 
[27] M. Heidarinejad, N. Mattise, M. Dahlhausen, K. Sharma, K. Benne, D. Macumber, L. Brackney, and J. Srebric, "Demonstration of reduced-order urban scale building energy models," Energy Build., vol. 156, pp. 17-28, 2017.

[28] J. Wright and A. Alajmi, "The robustness of genetic algorithms in solving unconstrained building optimization problems," in IBPSA 2005 - Int. Build. Perform. Simul. Assoc. 2005, no. November, (Montreal), pp. 1361-1368, 2005.

[29] E. Zitzler, L. Thiele, and M. Laumanns, "Performance Assessment of Multiobjective Optimizers: An Analysis and Review. IEEE Transactions on Evolutionary Computation," IEEE Trans. Evol. Comput., vol. 7, no. 2, pp. 117-132, 2002.

[30] V. Milić, K. Ekelöw, M. Andersson, and B. Moshfegh, "Evaluation of energy renovation strategies for 12 historic building types using LCC optimization," Energy Build., vol. 197, pp. 156-170, aug 2019.

[31] D. Tuhus-Dubrow and M. Krarti, "Genetic-algorithm based approach to optimize building envelope design for residential buildings," Build. Environ., vol. 45, pp. 1574-1581, jul 2010.

[32] M. Hamdy, A. T. Nguyen, and J. L. Hensen, "A performance comparison of multi-objective optimization algorithms for solving nearly-zero-energy-building design problems," Energy Build., vol. 121, pp. 57-71, jun 2016 .

[33] G. Campos Ciro, F. Dugardin, F. Yalaoui, and R. Kelly, "A NSGA-II and NSGA-III comparison for solving an open shop scheduling problem with resource constraints," IFAC-PapersOnLine, vol. 49, pp. 12721277, jan 2016 . 